\title{
Voltages in the network and inside industrial Plants. Case of PSA-Vigo
}

\author{
M. Pérez-Donsión ${ }^{(1)}$ and F.T. Oliveira ${ }^{(2,3)}$
}

\author{
1. Department of Electrical Engineering. University of Vigo. Vigo. Spain \\ 2. Department of Electrical Engineering, E.S.T.G., Polytechnic Institute of Leiria. Portugal \\ 3. INESC Coimbra (Institute for Systems Engineering and Computers at Coimbra). Portugal
}

\begin{abstract}
The main objective of this paper consists in presenting a survey of voltage sags and short interruptions in different places along the geography of Galicia measured throughout two years. Effects and the possible solutions of the voltage sags and short interruptions in one industrial installation, PSA-Vigo, that produce cars, are also addressed. Finally, we will establish the corresponding conclusions.
\end{abstract}

\section{Key words}

Voltage sags, short interruptions, power quality, voltage quality.

\section{Introduction}

Power systems have non-zero impedances, so every increase in current causes a corresponding reduction in voltage. Usually, these reductions are small enough that the voltage remains within normal tolerances. But when there is a large increase in current, or when the system impedance is high, the voltage can drop significantly. Nevertheless, most voltage sags are caused by increases in current.

It is possible to think of the power system as a tree, with the customer sensitive load connected to one of the twigs. Any voltage sag on the trunk of the tree, or on a branch leading out to the customer twig, will cause a voltage sag at its load. But a short-circuit out on a distant branch can cause the trunk voltage to diminish, so even faults in a distant part of the tree can cause a sag at a customer's load [1].

Standard EN 50160 indicates that voltage dips are generally associated with the start and end of a short circuit or other extreme current element in the system or installations connected to it. Thus, they may be due to faults occurring in customers' facilities or to faults in the general network. Their annual frequency depends mainly on the type of distribution network and the observation point. In addition, its distribution in one year can be very irregular.

Probably, the cause of most voltage sags is a short-circuit occurring either within the industrial facility under consideration or on the utility system. The magnitude of the voltage sag is mainly determined by the impedance between the faulted bus and the load, and by the method of connection of the transformer's windings [2]. The voltage sag lasts only as long as it takes the protective device to clear the overcurrent condition (typically up to 10 cycles) [3], therefore the duration of the sag is determined by the fault-clearing time of the protection system adopted. Moreover, if automatic reclosure is used by the utility, the voltage sag condition can occur repeatedly in the case of a permanent fault. Finally, depending on its magnitude and duration, the sag can cause an equipment trip, thus becoming a power quality problem [2].

The intensity of a short circuit (three-phase and singlephase) in the different nodes of a network is strongly dependent on the size of the latter, its lines, its transformers, on the degree of meshing, as well as on the size and location of the generating groups.

\section{Classification}

Voltage sags can be classified according to two quantities that are very useful for estimating their potential impact and the preventive measures that can be applied:

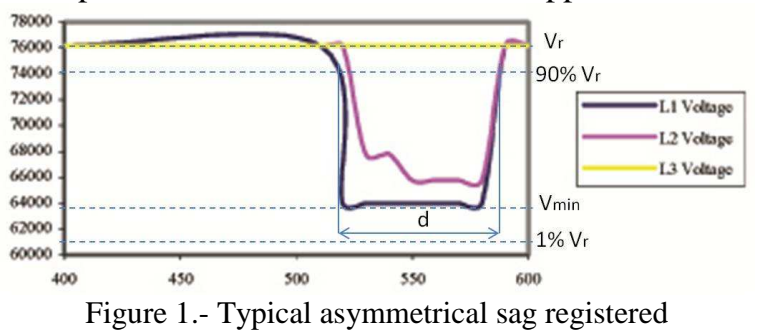

Duration, $\mathrm{d}$. In the case of three-phase lines, a voltage sag that occurs due to the same cause starts when the voltage in one of the phases decreases to a value between $90 \%$ of the reference voltage and the minimum residual voltage $\left(1 \% \mathrm{~V}_{\mathrm{r}}\right)$ and ends when the voltage in the three phases exceeds $90 \%$ of the reference voltage $\left(\mathrm{V}_{\mathrm{r}}\right.$ in Figure 1). This is called a complex voltage sag and is considered as a single event. An event with a depth above $90 \%$ is considered as a short interruption. The minimum duration 
of a voltage sag is considered by EN 50160 to be $10 \mathrm{~ms}$ (half a cycle), as it is the minimum period of time over which the RMS value of the voltage can be calculated, while the maximum is $3 \mathrm{~min}$.

Generally, the duration of the sag, d, of Figure 1, depends on the protection strategy adopted in the network, which varies from one network to another depending on the structure of the network and the grounding of the neutral.

Depth. The depth, or amplitude of a voltage sag, is defined as the percentage difference between the reference voltage, $\mathrm{V}_{\mathrm{r}}$, and the minimum voltage value reached during the voltage sag, $\mathrm{V}_{\min }$, or residual voltage. It is usually expressed by equation (1).

$$
\Delta V(\%)=\frac{V_{r} \quad V_{\text {min }}}{V_{r}} 100
$$

Voltage sags are, by nature, unpredictable in terms of location and time of occurrence. It is actually impossible to have fully representative statistics as regards the results of the measurements of voltage sags frequencies in all the European networks [4].

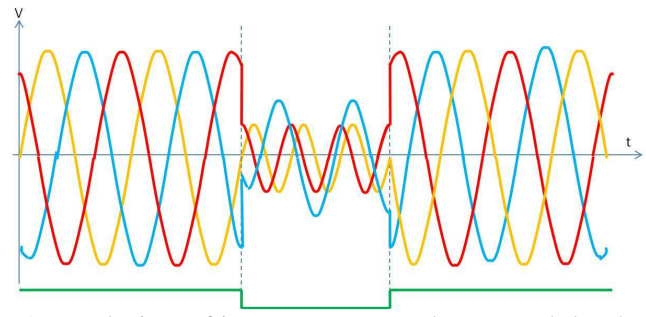

Figure 2. Evolution of instantaneous voltages and depth during an asymmetric voltage sag.

Voltage sags can be symmetrical or asymmetrical, depending on the type of fault or the type of overload that has caused them.

It is obvious that the shallower sags will require a prolonged duration to alter the operation of the equipment. A parameter called stress gap aggressiveness (Voltage Sag Aggressiveness or VSA), which represents the depth versus the duration of the event and could be an effective measure of the alterations caused by the voltage gap, has been suggested by many authors [5].

An index that can also be used to characterize the performance of a voltage sag is SARFI(x) (System Average RMS Frequency Index), which represents the number of voltage sags in a specific location, per year, with a minimum voltage (\%) below $\mathrm{x}$. This index can be calculated using equation (2).

$$
\operatorname{SARFZ}_{(X)}=\frac{N_{s}}{N_{y}}
$$

Where:

$\mathrm{N}_{\mathrm{s}}=$ Number of sags (of voltage $\mathrm{x}$ ) that have suffered user. $\mathrm{N}_{\mathrm{u}}=$ Number of users

The suggested values for $\mathrm{x}$ are $90 \%, 80 \%, 70 \%, 50 \%$, and $10 \%$ of the nominal value. The duration is computed by decomposing the SARFI(x) into three new indices: instantaneous (I), momentary (M) and temporal (T), which durations are $0.01-0.5 \mathrm{~s}, 0.5-3 \mathrm{~s}$ and 3-60 s, respectively.

It is also possible to consider the energy associated with voltage sags as seen from a given node or location. Two indices can be distinguished:

1. VSEI (Voltage Sag Energy Index), the power index of the voltage sag, which is the sum of energy not supplied during all voltage sags measured over a given period.

2. AVSEI (Average Voltage Sag Energy Index), the average power index of the voltage sag, which is the average energy not supplied due to voltage sags in a given period.

In the general case, the energy loss in a three-phase voltage sag can be calculated according to equation (3).

$$
W=\left(1-V a_{p u}\right)^{2} \cdot t_{a}+\left(1-V b_{p u}\right)^{2} \cdot t_{b}+\left(1-V c_{p u}\right)^{2} \cdot t_{c}
$$

Where:

$\mathrm{Va}_{\mathrm{pu}}, \mathrm{Vb}_{\mathrm{pu}}$ and $\mathrm{Vc}_{\mathrm{pu}}=$ residual voltages in each phase in values per unit.

$t_{a}, t_{b}$ and $t_{c}=$ Duration of the voltage sag in each phase.

There is another set of indices based on the sag's boundary area (Sag Limit Area, SLA). Figure 3 shows diagrams representing the same voltage sag (Sag event, $S E_{n}$ ). The device on the left measures the depth of the event $\left(\mathrm{d}_{\mathrm{n}}\right)$ and is called Sag limit device $(S L)$, while the one on the right samples the sag with a sufficient level of detail to sketch the time profile of the sag and provide the total area of the event $\left(\mathrm{a}_{\mathrm{n}}\right)$; the latter is a Sag area device $(S A)$, more expensive than the first one. Thus, it is possible to define a set of SLA indices for each type of monitoring device. This group of indices is established in order to satisfy all those who wish to have a single numerical indication about the quality of voltage, in a particular location, and in which the counting of events, depth, duration or area is included. To achieve this level of detail there are various techniques available as duration-depth histograms, analysis of the event-failure correlation (of the equipment), study of the profile of the sag, analysis of the symmetric components, etc.

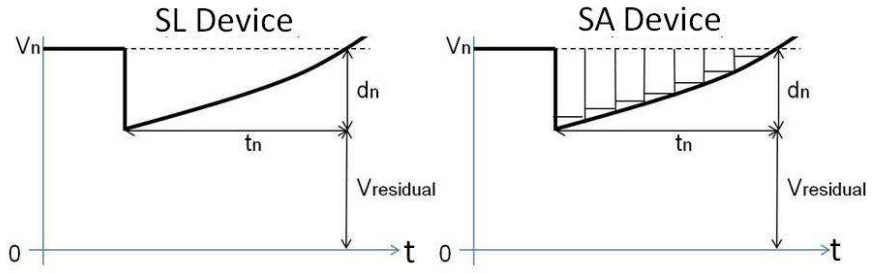

Figure 3. Measurement of a sag by two devices of different characteristics

Each of the indices described in Table 1 has a purpose. It is necessary to have two groups of indexes ( $S L$ and $S A$ ) as the results are likely to be quite different, because the monitoring devices are also different. It can be anticipated that the number of events, the average depth per sag, the average duration per sag and the average area per sag will be the most useful indicators in terms of voltage quality [5]. 
Table 1. Set of indices SL and SA.

\begin{tabular}{|c|c|c|}
\hline SL Device & $\begin{array}{c}\text { Measured } \\
\text { magnitude }\end{array}$ & SA Device \\
\hline$S L_{c}=\sum S E_{n}$ & $\begin{array}{c}\text { Number of events } \\
\text { (Sag events) }\end{array}$ & $S A_{c}=\sum S E_{n}$ \\
\hline$S L_{a d}=\sum d_{n}$ & $\begin{array}{c}\text { Total (cumulative) } \\
\text { depth of sags }\end{array}$ & $S A_{a d}=\sum d_{n}$ \\
\hline$S L_{d}=\frac{\sum d_{n}}{S L_{c}}$ & $\begin{array}{c}\text { Average depth per } \\
\text { sag }\end{array}$ & $S A_{a d}=\sum d_{n}$ \\
\hline$S L_{a t}=\sum t_{n}$ & $\begin{array}{c}\text { Total (cumulative) } \\
\text { duration of sags }\end{array}$ & $S A_{a t}=\sum t_{n}$ \\
\hline$S L_{t}=\frac{S L_{a t}}{S L_{c}}$ & $\begin{array}{c}\text { Average duration } \\
\text { per sag }\end{array}$ & $S A_{t}=\frac{S A_{a t}}{S A_{c}}$ \\
\hline$S L_{a a}=\sum t_{n} \cdot d_{n}$ & $\begin{array}{c}\text { Total (cumulative) } \\
\text { area of sags }\end{array}$ & $S A_{a a}=\sum a_{n}$ \\
\hline$S L_{a}=\frac{S L_{a a}}{S L_{c}}$ & $\begin{array}{c}\text { Average area per } \\
\text { sag }\end{array}$ & $S A_{a}=\frac{S A_{a a}}{S A_{c}}$ \\
\hline
\end{tabular}

The following is a brief explanation of the SL indices, which also applies to SA:

1. The $S L_{c}$ index provides the amount of sags for a given sampling period.

2. The $S L_{a d}$ index provides the aggregate depth, in volts per unit (p.u.), of all sags in the sampling period.

3. The $S L_{d}$ index provides the mean depth per sag, in volts, of all sags in the sampling period.

4. The $S L_{a t}$ index provides the cumulative duration, in seconds, of all sags in the sampling period.

5 . The $S L_{t}$ index provides the average duration per sag, in seconds, of all sags in the sampling period.

6. The $S L_{a a}$ index provides the aggregate area in voltsseconds of all sags in the sampling period. This is an indicator of the total energy lost (in resistive loads) due to the voltage sags.

7. The $\mathrm{SL}_{\mathrm{a}}$ index provides the average area per sag of all sags in the sampling period. This is an indicator of the average energy lost (in resistive loads) per sag.

Finally, the parameter used in the DEC (Detroit Edison Company), through which it is intended to characterize a voltage gap by the mean value of the voltage drop in the three phases, that is to say by a single Sag Score parameter, in which the voltages in the three phases are involved, according to equation (4) (voltage values must be expressed in a per unit basis).

$$
S=1-\frac{V_{a}(t)+V_{b}(t)+V_{c}(t)}{3}
$$

\section{Measurements}

Taking a series of measurements provided by a Spanish utility, a voltage sags and short interruptions classification was made, attending to different parameters. This study was made in low, medium and high voltage lines.
At this point it should be stated that due to the measurement method selected, it is necessary to take into account the uncertainty of the measurement that affects the results, which has to be considered, especially for shorter events [5].

The samples recorded were obtained in several points throughout the Spanish region of Galicia for two years, according to an annual strategic plan in which different places deemed representative of power quality along the distribution network were studied; and are presented in Figure 4. Some sites were surveyed due to complains by industrial customers, to find the source of a problem inside an industrial plant and suggest a possible solution, or simply to assess the power quality of the supply [6].

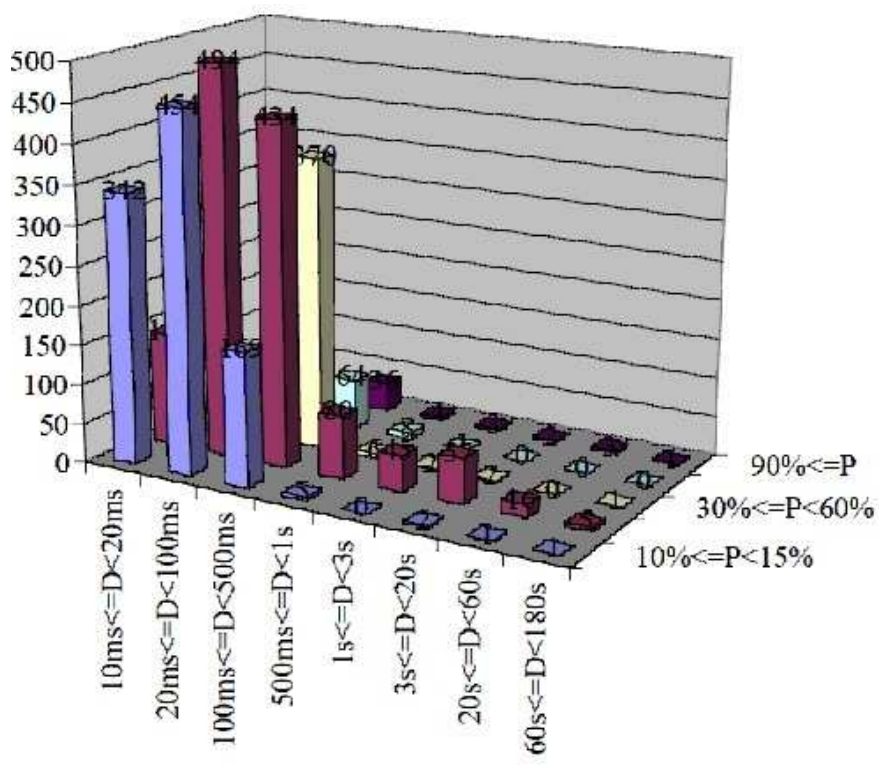

Figure 4. Voltage sags registered along two years

When compiling statistics, voltage sags should be measured and detected in accordance with the Standard EN 61000-4-30, by reference to the rated supply voltage. The characteristics of the gaps to be determined, according to this standard, are the residual voltage and duration.

In low voltage networks, in the case of a three phase system of four conductors, phase-neutral voltage should be taken into account; for a three phase system of three conductors the phase-phase voltage should be taken into account; in the case of a single phase connection the supply voltage phase-phase or phase-neutral, (depending on the user connection) should be taken into account.

By convention, the starting threshold of the sag is equal to $90 \%$ of the rated voltage. Hysteresis is usually $2 \%$. The threshold of the voltage sag is a percentage of $\mathrm{V}_{\mathrm{din}}$ or of the $\mathrm{V}_{\text {sr }}$ sliding voltage reference. The reference voltage in use must be declared by the user.

The sliding reference voltage $\mathrm{V}_{\mathrm{rs}}$ is not generally used in low voltage networks. For more information and recommendations see the Standard IEC 61000-2-8. 


\section{Mitigation/Elimination}

Transmission and distribution network operators cannot completely eliminate the voltage sags, but they may reduce their number, depth and duration through better maintenance of networks, the use of technologies more immune to atmospheric discharges, increasing short circuit capacity $\left(\mathrm{S}_{\mathrm{cc}}\right)$ and faster action of short circuit protection elements. Actions undertaken to reduce voltage sags shall be considered balancing cost with the importance of a good level of the continuity of the electrical supply. In any case, it is not possible to eliminate the voltage sags completely, nor to reduce them beyond a certain limit.

Most substations have several transformers and multiple feeders for each transformer. When a fault occurs in one of the circuits, a decrease of the supply voltage in the substation occurs. This affects many other feeders, not just that where the fault has occurred. Depending on the rigidity of the electrical transport system, other branches in substations and even the substations themselves may experience phenomena associated with overcurrent, and multiples switches can trip to eliminate the same fault [5].

Faults in the network can occur both in the transmission network and in the distribution network. Outages in the transmission network can in turn affect a large number of customers, because the transmission network is meshed and supplies multiple substations, but take a shorter time to be eliminated, due to the quick action of the switches. So, even if users are hundreds of kilometres away from the location of the fault, they may still experience a voltage sag, suffering from equipment malfunction. A fault on the supply side within the transmission system shall not, under normal conditions, cause an interruption to the consumer. Moreover, it should be borne in mind that transmission systems are strongly meshed, unlike distribution systems, which are normally radial.

The magnitude of the voltage sag is determined, among other factors, by the location of the fault causing by this event. The faults in a power line that providing power to a particular user can be divided into two groups:

1. Those located between the customer and the substation (which will drop the voltage value to zero at the customer's location).

2. Those located downstream with respect to the customer (which are those that will cause a voltage sag in the customer, of greater or lesser depth, depending on the distance to the fault).

However, faults in the user's power supply are much less frequent than those taking place on the lines adjacent to it, simply because of a question of probabilities (one line versus many).

The faults further upstream, closer to the substation will cause the bus voltage to fall more sharply than those that take place at points distant from the substation. The bus voltage during a fault is determined, in an approximate form, by the voltage divider that is established between the impedance of the source, usually the impedance of the transformer, and the impedance of the line that goes from the substation busbar to the fault. The further away from the substation is the location of the fault, the greater the impedance that exists on the line and, consequently, the voltage value on the bar will also be higher.

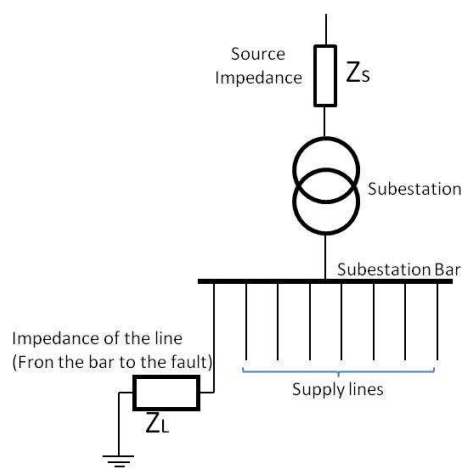

Figure 5. Typical scheme of a power line with a fault in the line to the left of the bar.

If $U_{S}=1$ p.u is considered, the per unit voltage of the busbar is a function of both the impedance of the line $\left(\mathrm{Z}_{\mathrm{L}}\right)$ between the bar and the location of the fault, and the impedance of the source $\left(Z_{S}\right)$, as can be seen in equation (5) and Figure 6.

$$
U_{B}=\frac{Z_{L}}{Z_{L}+Z_{S}} U_{S}
$$

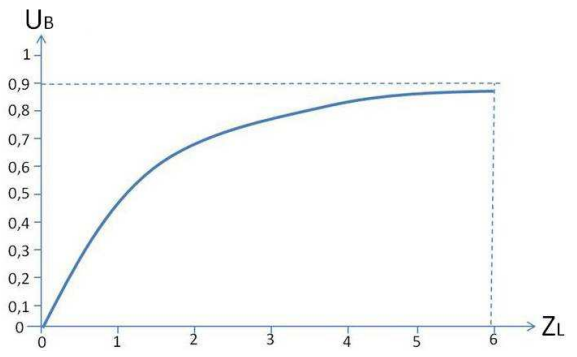

Figure 6. Voltage (p.u.) in the busbar for a fault in the power line as a function of the line impedance between the busbar and the fault.

In the case of a medium voltage supply, it is assumed that most users have a three-phase connection, so a voltage sag in the three phases is not more severe than an event in one of the phases. When simultaneous sags occur in several phases, the one with the greatest depth is the one used for the characterization of the event. This procedure is called phase aggregation.

\section{Case of PSA-Vigo}

The PSA Factory in Vigo is a vehicle manufacturing plant belonging to the French group PSA Peugeot-Citroën, located in the city of Vigo (Spain). The factory started its activity in 1958 as a Citroën factory (Citroën Hispania, S.A.). The move to Balaídos, a district of Vigo, took place in August 1959 [7].

In 2017 the PSA Peugeot Citroën plant in Vigo had a production volume of 435000 vehicles and 26830 collections (vehicles piece by piece) [8]. In 2018, 
however, production fell slightly, and it is estimated that it will have produced 410.000 vehicles. However, between 2020 and 2021, with the K9 and V20, it plans to reach its "record production capacity" and to have to increase shifts and staff [9].

The factory is considered one of the basic pillars of the Galician economy and represents $30 \%$ of Galician exports [7].

In the automotive industry, with a great volume of production, the cost due to power quality problems, such as voltage sags and interruptions, is due not so much to the cost of raw materials involved in the production which was irrevocably lost, but mostly to the cost of personnel rendered unproductive through production line stoppage and restart time.

The manufacturing of an automobile bodywork begins with the coupling to the system of a bobbin of laminated steel. Big engines turning at constant speed unroll the bobbin and feed it to the system.

The first step is the cutting. Pressure is applied along the cutting lines by a hydraulic press to obtain individual plates. These plates go on to the zone of deep drawing. With this process one gives shape to the steel, for it, a set of dies is placed in the press depending on the required piece.

Each die is capable of cutting, drilling and shaping a certain piece, and for that it is the most important machine of the workshop of presses, and because of it its maintenance and adjustment being vital. Voltage dips can change the speed of the engines, being able to provoke its stoppage, or cause a clogging torque to the machinery.

The process of restarting takes, on average, a few hours, and in such a coordinated, linear process and with a maximum interaction between processes, a stoppage in any point of the line of production supposes stopping the complete line.

All the aspects of assembling in the automotive industry, from the cadence up to the quality and the number of units, require precise coordination and a constant supply of parts.

The process of assembling it is carried out in big production halls where a high number of mechanical arms place, pierce and the weld together the pieces obtained in the production phase.

The PSA-Vigo is electrically supplied by a $132 \mathrm{kV}$ power network (Figure 6), and each year a great number of incidents in the activity of the factory occur due to voltage sags that take place to consequence, basically, of faults generated throughout the electrical lines that cross the provinces of Pontevedra and Orense.

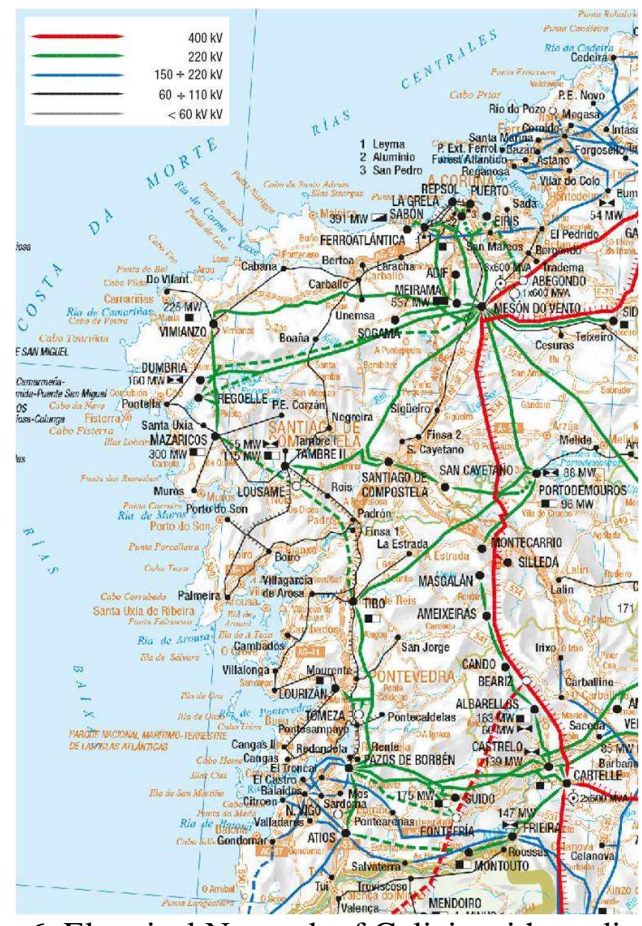

Figure 6. Electrical Network of Galicia with medium and high voltage lines.

From 2010 up until the present data, an average number of 60 annual disturbances have been registered at the factory, causing production stoppages of up to two hours and provoking IT breakdowns, loss of information and imbalances in the processes.

The worst year for PSA-Vigo was 2017, during which 115 voltage dips/interruptions were registered, with one particularly critical day, May $26^{\text {th }}$, when due to these events 347 cars and workshops stopped and the production lines were stopped for nine hours.

The high degree of automation of PSA-Vigo, with a large number of robots, Figure 7, leads to more efficiency but also to added vulnerability in the presence of a voltage sag.

Several things can be done by the utility, customers and equipment manufacturers to reduce the number and severity of voltage sags and to reduce the sensitivity of the equipment to voltage sags. In reference [5] the author presents a considerable number of solutions at different cost.

The IT and control equipment, which is highly sensitive to voltage sags, may severely affect the tasks of assembling, and protection devices are activated in order to protect the equipment and the components. The costs associated are, as in the production, mostly due to stoppage times.

To avoid these situations, the factory has invested in internal improvements to ride-through voltage sags, but the best option to obtain a reliable energy supply is thought to be its connection to the $220 \mathrm{kV}$ network that passes through nearby city of Porriño. 


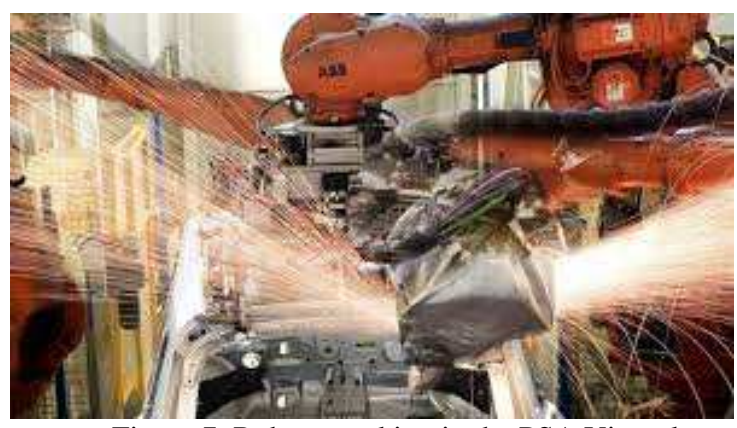

Figure 7. Robots working in the PSA Vigo plant.

Many power quality problems occurring in a node of the network (harmonic, flicker, sags, etc.) and their effects are inversely proportional to the short circuit capacity of the network at that node; therefore, if the factory is connected to the network of $220 \mathrm{kV}$, with a higher short circuit capacity than the network of $132 \mathrm{kV}$, then it will not suffer such severe consequences of poor power quality.

On the other hand, the connection to the $220 \mathrm{kV}$ network would mean annual savings of one million Euros in the PSA-Vigo's electricity bill, which is something the company has also put before the Secretary of State for Energy to argue its request to a $220 \mathrm{kV}$ connection; its effect on the reliability of the electricity supply is important so as not to see the production process altered, as in other plants in the group, such as Figueruelas (Zaragoza) and almost all the car factories in Spain [10].

The Spanish Transmission network operator, REE, itself considers this action necessary, which is already reflected in its 2015-2020 planning (New Vigo 2020 Project), but so far it has not materialized, pending that the Ministry of Ecological Transition approves the "exceptionality" of the project to authorize the investment, which amounts to 70 million Euros, since part of this link would have to be underground, which makes the works more expensive.

This project is crucial both for the Balaídos (Vigo) plant and for the future needs of the city of Vigo, the only large Spanish city connected to a $132 \mathrm{kV}$ network.

On Figure 3 of reference [6] the authors illustrate four alternative solutions. As this chart indicates, it is generally less costly to tackle the problem at its lowest level, close to the load, because solutions such as enhanced equipment specifications cost a small number of Euros since sensitive parts have very low current ratings. As solutions at higher levels of available power are entertained, the solutions often become more expensive.

\section{Conclusions}

The best solution to address a problem involving voltage sags or short interruptions depends on the customer's particular circumstances and the distribution network characteristics.

Equipment included in industrial processes, such as in PSA-Vigo, may be particularly susceptible to voltage sags. The reason for this is that such equipment is interconnected, and a failure of any component can cause the shutdown of the manufacturing line or the entire industrial plant.

It should also be borne in mind that different categories of equipment and even different brands of equipment within the same category (for example, two different models of motor speed control circuits) may have completely different sensitivities to voltage sags. This makes it difficult to develop a single standard that defines the sensitivity of equipment included in industrial processes.

Robots need constant voltage to operate properly and within certain safety conditions. Any sudden variation in voltage, especially that caused by the sags, can lead to the execution of unsafe robot or machine operations. Therefore, these types of machines are often adjusted to stop working from levels around $90 \%$ of the rated voltage.

The wide range of sensitivities presented by industrial equipment underlines the importance of collaborating with the manufacturers to ensure that the equipment can function within the electromagnetic environment in which it will be used, and it is possible to develop specifications based on realistic power system conditions. It is also important to understand that the entire process in an industrial plant can depend on the sensitivity of a single piece of equipment. Together, the process involves control circuits, contactors, robots, logical devices, etc, which are, in turn, integrated, each and every one of them, in the operation of the plant. This can also make it difficult to identify the sensitive part in a process, after the whole process has been stopped.

The fact that voltage sags are not usually destructive for electrical equipment does not detract from the severity of their effects, as they can cause serious damage to the production generated by these pieces of equipment. Stoppages in production processes generate economic losses and defects in manufactured products.

\section{References}

[1] Alex McEachern. Sources of voltage sags. Power Standards Testing Laboratory, 2000.

[2] Ambra Sannino. Mitigation of voltage sags and short interruptions through distribution system design. Dept. of Electrical Engineering University of Palermo, pp 1-6, 2000

[3] Pacific Gas and Electric Company. Short duration voltage sags can cause disruptions PG\&E, pp 1-12, Junio 2000.

[4] AENOR, Norma UNE-EN 50160: Características de la tensión suministrada por las redes generales de distribución, marzo de 2011

[5] Manuel Pérez Donsión, Calidad de la Energía Eléctrica, Ibergarceta Publicaciones, S.L. Madrid 2016. ISBN: 978-841622-858-4

[6] Nicolás Louzán Pérez, Manuel Pérez Donsión, "Technical Methods for the Prevention and Correction of Voltage Sags and Short Interruptions inside the Industrial Plants and in the Distribution Networks". International Conference on Renewable Energy and Power Quality (ICREPQ’03), Vigo April 9-12 2003.

[7] https://es.wikipedia.org/wiki/F\%C3\%A1brica_PSA_de_Vigo

[8] Auto Revista. On January $2^{\text {nd }}, 2018$

[9] Europa Press. On September $18^{\text {th }}, 2018$

[10] Faro de Vigo. On February $7^{\text {th }}, 2019$ 